\title{
Dinâmica da paisagem da bacia hidrográfica do Rio Marapanim, Pará, Brasil
}

A mesorregião nordeste paraense se destaca pela substituição das florestas nativas e/ou secundárias por atividades agropecuárias, com destaque para a atuação da agricultura familiar e utilização de técnicas agrícolas rudimentares, tal como o processo de derruba e queima. O objetivo do presente estudo foi analisar a dinâmica da paisagem da bacia do rio Marapanim, nordeste do Pará, com base nas transições e permanências das classes de cobertura vegetal e uso da terra. Para isso, foram obtidas imagens do satélite Landsat 5 e 8 dos anos de 1988, 1998, 2008 e 2017, as quais foram classificadas pelo algoritmo de Máxima Verossimilhança, e assim quantificadas as classes de uso do solo. Posteriormente, foi feita a análise da Detecção de Mudança entre as classes ao longo do período, visando assim identificar o percentual de uma classe que foi convertida em outra, bem como que permaneceu inalterado. Os resultados mostraram que houve diminuição de quase $44 \%$ das áreas de vegetação densa e de $21,3 \%$ das áreas de vegetação secundária na bacia hidrográfica. As áreas de agropecuária aumentaram em $412,5 \%$, do primeiro ao último ano de análise. A dinâmica da paisagem mostrou que a vegetação densa foi convertida principalmente para vegetação secundária, enquanto que as classes de solo exposto e vegetação secundária foram convertidas prioritariamente para agropecuária no último período de análise.

Palavras-chave: Detecção de mudança; Recursos naturais; Uso da terra.

\section{Landscape dynamics of the Marapanim River watershed, Pará, Brazil}

The northeastern mesoregion of Paraense stands out for the substitution of native and/or secondary forests for agricultural activities, with emphasis on the performance of family agriculture and the use of rudimentary agricultural techniques, such as the process of knocking and burning. The objective of the present study was to analyze the landscape dynamics of the Marapanim river watershed, northeast of Pará, based on the transitions and persistence of vegetation cover and land use classes. To this end, Landsat satellite 5 and 8 images of the years 1988, 1998, 2008 and 2017 were retrieved and analyzed through maximum likelihood classification. Subsequently, a Change Detection analysis was performed between the classes throughout the period studied. The results showed that there was a decrease of almost $44 \%$ of dense vegetation areas and $21.3 \%$ of secondary vegetation areas. Agricultural and livestock areas increased by $412.5 \%$ from the first to the last year analyzed. The dynamics of the landscape showed that dense vegetation was converted mainly into secondary vegetation, while the classes of exposed soil and secondary vegetation were converted primarily into agriculture and cattle raising areas in the last period of analysis.

Keywords: Change detection; Natural resources; Land use.

Topic: Desenvolvimento, Sustentabilidade e Meio Ambiente

Reviewed anonymously in the process of blind peer
Received: 12/05/2020

Approved: 05/06/2020
Ádanna de Souza Andrade (iD)

Instituto Federal do Pará, Brasil

http://lattes.cnpq.br/8867021322241509

http://orcid.org/0000-0002-7516-3862

adanna.eng.ambiental@gmail.com

Suezilde da Conceição Amaral Ribeiro (i)

Universidade do Estado do Pará, Brasil

http://lattes.cnpq.br/3519207052266437

http://orcid.org/0000-0002-1661-7609

suziar@yahoo.com.br

Bruno Wendell de Freitas Pereira (1)

Universidade Federal Rural da Amazônia, Brasil

http://lattes.cnpq.br/3555944059894165

http://orcid.org/0000-0002-3823-6292

brunowendell@yahoo.com.br

\author{
Valter Vinicius Pereira Brandão (iD \\ Universidade Federal do Pará, Brasil \\ http://lattes.cnpq.br/0828953466177169 \\ http://orcid.org/0000-0003-0924-2885 \\ viniciuspgeo@gmail.com \\ Bruno Monteiro Ferreira (ic) \\ Universidade Federal Rural da Amazônia, Brasil \\ http://lattes.cnpq.br/5894859432048045 \\ http://orcid.org/0000-0002-1708-9318 \\ brunoftal@gmail.com
}

\section{Referencing this:}

ANDRADE, Á. S.; RIBEIRO, S. C. A.; PEREIRA, B. W. F.; BRANDÃO, V. V. P.; FERREIRA, B. M.. Dinâmica da paisagem da bacia hidrográfica do Rio Marapanim, Pará, Brasil. Revista Ibero-Americana de Ciências Ambientais, v.11, n.4, p.395-405, 2020. DOI: http://doi.org/10.6008/CBPC2179-6858.2020.004.0032

DOI: $10.6008 / C B P C 2179-6858.2020 .004 .0032$ 


\section{INTRODUÇÃO}

A paisagem assumiu diversificados conceitos, tendo sido estudada sob diferentes ênfases ao longo do tempo (MAXIMIANO, 2004). Adota-se nesse estudo o conceito de Bertrand (2004), no qual a paisagem é resultado de uma combinação dinâmica de elementos físicos, biológicos e antrópicos, que a fazem se modificar constantemente ao longo do tempo. Assim, a paisagem não se limita ao 'natural', mas sim uma paisagem total, que integra as implicações da ação antrópica.

Nesse contexto, a bacia hidrográfica se insere como um dos elementos da paisagem, sendo definida como uma área de captação natural da precipitação, composta por um conjunto de superfícies de vertentes e uma rede de drenagem que faz convergir o escoamento para um único ponto de saída, denominado exutório (TUCCI, 2001). A bacia hidrográfica abrange uma interação da água com o meio físico, biótico e socioeconômico, e por esse motivo vem sendo adotada para fins de planejamento e gestão dos recursos hídricos (OLIVEIRA et al., 2018; CARVALHO, 2014).

Nessa concepção sistêmica em que se insere a bacia hidrográfica, deve-se enfatizar que a mesma é passível de modificações pelas ações antrópicas, podendo comprometer a quantidade e qualidade da água disponível aos usuários da bacia (MOREIRA et al., 2015). Essas modificações ocorrem em decorrência das variadas formas de utilização do espaço pelo homem, baseadas em seus interesses próprios e com diferentes padrões espaço-temporais, o que caracteriza o uso da terra da região (VALE et al., 2015).

A Amazônia, maior floresta tropical remanescente do mundo, destaca-se em âmbito global por fornecer bens econômicos (madeira, produtos agrícolas) e serviços ecossistêmicos (tais como regulação climática e conservação da biodiversidade) fundamentais ao bem-estar de mais de 30 milhões de pessoas que abrangem esse bioma (GARDNER et al., 2013). No entanto a região amazônica sofreu ao longo de seu processo de ocupação, profundos desequilíbrios ambientais, principalmente em suas paisagens naturais, decorrentes de diferentes formas de uso e ocupação da terra atrelado aos aspectos socioeconômico e político (SAMPAIO et al., 2017). A substituição dos ambientes naturais tem dado origem às paisagens antropizadas, onde os sistemas de produção caracterizam-se pela remoção da cobertura vegetal e não valorização dos recursos florestais (FEARNSIDE, 2001).

Atualmente, um dos principais problemas ambientais que acomete essa região têm sido a expansão das fronteiras agrícolas e as áreas destinadas à pecuária, que levam à descaracterização da vegetação original (PEREIRA et al., 2015). Nesse sentido, o nordeste do estado do Pará se insere nesse contexto, pois é uma das mais antigas áreas de colonização da Amazônia, que se intensificou com a consolidação da estrada de ferro Belém-Bragança no século XIX (WATRIN et al., 2009). Assim, a construção da estrada de ferro e o avanço da frente de colonização foram responsáveis pela substituição da floresta primária nessa região, além da ferrovia ter facilitado o início de uma agricultura extensiva (VIEIRA et al., 2007).

Nesse âmbito, é essencial o desenvolvimento de estudos relacionados à dinâmica de uso e ocupação do espaço em áreas da Amazônia e mais especificamente no nordeste paraense, e nesse sentido, as técnicas de geoprocessamento, associadas ao Sistema de Informações Geográfica (SIG) vêm sendo largamente 
utilizadas na identificação, mapeamento e estimativas dos usos da terra, bem como em análises das modificações da paisagem ao longo do tempo (PRINA et al., 2016; WATRIN et al., 1998; SOUZA et al., 2011; PEREIRA et al., 2015; VALE et al., 2015; NASCIMENTO et al., 2017).

A bacia hidrográfica do rio Marapanim localiza-se em uma área sob forte pressão antrópica, o que comprometeu ao longo dos anos, a qualidade ambiental tanto no que diz respeito à cobertura vegetal quanto aos recursos hídricos. Esse panorama culminou com a criação, em março de 2017, do primeiro comitê de bacia do estado do Pará: o Comitê de Bacia Hidrográfica do Rio Marapanim (CBHRM), visando solucionar os conflitos de natureza hídrica que ocorrem na área de abrangência da bacia.

O objetivo desse trabalho é analisar, ao longo de 29 anos, a dinâmica da paisagem da bacia hidrográfica do rio Marapanim, utilizando-se, para isso, técnicas de geoprocessamento, e identificando as áreas de maior fragilidade, visando assim, auxiliar os gestores quanto a uma melhor tomada de decisão no uso dos recursos naturais.

\section{MATERIAIS E MÉTODOS}

\section{Caracterização e localização da área de estudo}

A bacia hidrográfica do rio Marapanim, objeto desse estudo, localiza-se na mesorregião nordeste paraense e nas microrregiões do Salgado, Bragantina e Castanhal, entre as coordenadas geográficas $0^{\circ} 32^{\prime} 19.075^{\prime \prime}$ e $1^{\circ} 18^{\prime} 36.961^{\prime \prime S}$ e $47^{\circ} 31^{\prime} 45.232^{\prime \prime}$ e $48^{\circ} 2^{\prime} 20.954^{\prime \prime W}$ (Figura 1 ), abrangendo 12 municípios, em um território ocupado por mais de 500.00 habitantes (IBGE, 2017).

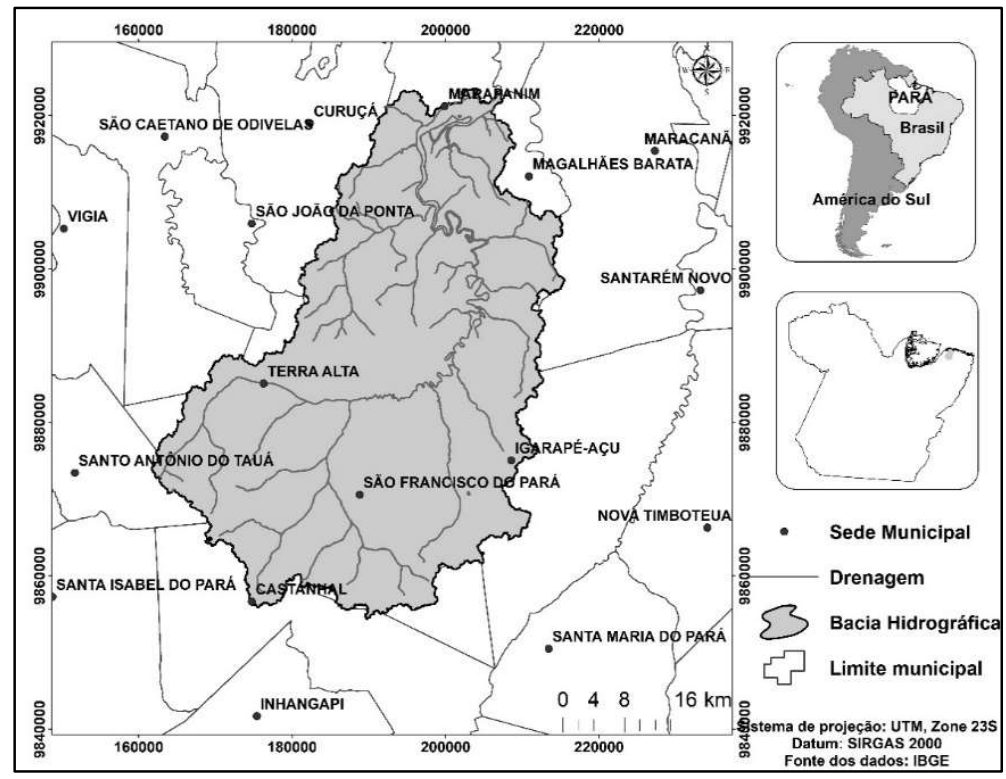

Figura 1: Localização da bacia hidrográfica do rio Marapanim/PA.

A bacia hidrográfica do rio Marapanim está inserida na área de endemismo Belém, a qual foi considerada a mais desmatada em um estudo de Braz et al. (2016), quando encontraram um percentual de $62,2 \%$ de desmatamento nessa área, sendo classificada em uma situação preocupante, necessitando de intervenção urgente do poder público.

O Clima dessa região é do tipo “Am” de acordo com a classificação de Köppen (ALVARES et al., 2014), 
a vegetação original é do tipo floresta ombrófila densa de terras baixas (IBGE, 2012) e os solos predominantes são caracterizados por serem bem drenados e de baixa fertilidade natural, majoritariamente os Latossolos amarelos distróficos (EMBRAPA, 2013).

Para a delimitação dessa bacia foram utilizados dados do Shuttle Radar Topography Mission (SRTM), com resolução espacial de 30 metros, obtidas no banco de dados Topodata do Instituto Nacional de Pesquisas Espaciais $^{1}$, por meio de imagens do tipo Modelo Digital de Elevação (MDE) de número 00S48ZN e 01S48ZN articulada às cartas na escala 1:250.000. A delimitação foi feita no Sistema de Informação Geográfica (SIG) Arcgis 10.1, por meio da ferramenta Hidrology.

\section{Aquisição e processamento digital de imagem}

Para a análise da dinâmica do uso do solo, foram utilizadas imagens do satélite Landsat 5 (referentes aos anos de 1988, 1998, 2008) e Landsat 8 (referente a 2017), ambas correspondentes à órbita/ponto 223/61 (Tabela 1), adquiridas no site do Serviço geológico dos Estados Unidos ${ }^{2}$ e reprojetadas para o hemisfério Sul, utilizando-se o Sistema de projeção UTM, Datum WGS 84, Zona 23 .

Tabela 1: Imagens utilizadas na classificação.

\begin{tabular}{lllll}
\hline Ano & Data da imagem & Órbita/Ponto & Sensor & Satélite \\
\hline 1988 & $04 / 06 / 1988$ & $223 / 61$ & TM & Land Sat 5 \\
1998 & $19 / 08 / 1998$ & $223 / 61$ & TM & Land Sat 5 \\
2008 & $13 / 07 / 2008$ & $223 / 61$ & TM & Land Sat 5 \\
2017 & $06 / 07 / 2017$ & $223 / 61$ & OLI & Land Sat 8 \\
\hline
\end{tabular}

Fonte: USGS (2017).

A bandas foram submetidas à uma correção atmosférica pelo método DOS (Dark Object Subtration) proposto por Chavez (1988 e 1989), para corrigir o efeito do espalhamento atmosférico na radiância da cena.

O banco de dados criado a partir das imagens de satélite, dos anos de 1988, 1998, 2008 e 2017 foi efetuado nos softwares Envi versão 5.2 e ArcGIS versão 10.1 (ESRI, 2010). Na imagem Landsat 8 foi realizada uma transformação radiométrica de 16 bits para 8 bits. Foi realizada a composição colorida falsa cor R5G4B3 para as imagens Landsat 5 e composição R6G5B4 para a imagem Landsat 8. As imagens foram interpretadas, de modo a identificar as classes de feições presentes na área de estudo.

\section{Trabalhos de campo}

Os trabalhos realizados no campo compreenderam o reconhecimento e caracterização da paisagem da área de estudo, através da correlação das classes temáticas definidas a partir da interpretação das imagens com os padrões de cobertura vegetal observados no campo. Foram realizadas visitas de campo no período de 12 a 23 de junho de 2017 onde na ocasião foram feitos registros fotográficos da área e coleta de pontos de controle com GPS de navegação (Garmin 62sc).

\footnotetext{
${ }^{1}$ http://www.webmapit.com.br

2 https://earthexplorer.usgs.gov/ 


\section{Classificação supervisionada}

A classificação foi realizada com base em uma máscara vetorial referente ao shape da bacia hidrográfica, utilizando-se o algoritmo de Máxima-verossimilhança (Maxrver), a partir de informações espectrais através das bandas de refletância 3,4,5 do Landsat 5 e 4,5,6 do Landsat 8. Após a classificação, foi feita a correção manual dos pixels classificados erroneamente em determinada classe, por meio da função Classedit do software ENVI 5.2. A acurácia da classificação foi avaliada a partir da análise da matriz de confusão e do índice Kappa, o qual foi obtido acima de 0,85 para todos os anos de análise, sendo considerada excelente (LANDIS et al., 1977).

\section{Dinâmica espaço-temporal}

A quantificação das áreas ocupadas pelas classes de vegetação e uso da terra em cada ano, foi realizada por meio da função 'Estatística de Classes' do software Envi 5.2. Posteriormente foi realizada a análise da dinâmica do uso da terra nos períodos de 1988 a 1998, de 1998 a 2008 e de 2008 a 2017, por meio da tabulação cruzada entre imagens temáticas das datas consecutivas, utilizando-se o módulo "Detecção de mudança" do software, a partir da análise das matrizes de transição (ROMERO-RUIZ et al., 2012).

\section{RESULTADOS}

\section{Uso do solo na bacia hidrográfica}

Foram identificadas 6 (seis) classes de cobertura vegetal e uso do solo, sendo 5 (cinco) dessas comuns a todos os anos: Floresta densa, vegetação secundária, solo exposto, agropecuária e água. A classe de nuvem/sombra fez-se presente nas imagens de satélite nos dois primeiros anos e a classe áreas alteradas, a qual representa áreas de degradação florestal devido ao intenso uso do solo, foi identificada espectralmente nos anos de 2008 e 2017 (Tabela 2).

Tabela 2: Área e percentual ocupado por cada classe de uso do solo de 1988 a 2017.

\begin{tabular}{l|ll|ll|ll|ll}
\hline CLASSES & $\mathbf{1 9 8 8}$ & $\mathbf{\%}$ & $\mathbf{1 9 9 8}$ & $\mathbf{\%}$ & $\mathbf{2 0 0 8}$ & $\mathbf{\%}$ & $\mathbf{2 0 1 7}$ & $\mathbf{\%}$ \\
\hline Vegetação Secundária & 1152,7 & 53,83 & 1069,79 & 49,96 & 941 & 43,95 & 906,92 & 42,35 \\
Solo Exposto e Área Urbana & 492,15 & 22,98 & 558,18 & 26,07 & 506,02 & 23,63 & 311,57 & 14,55 \\
Floresta Densa & 292,48 & 13,66 & 287,45 & 13,42 & 272,08 & 12,71 & 164,03 & 7,66 \\
Agropecuária & 123,44 & 5,76 & 141,13 & 6,59 & 326,39 & 15,24 & 632,16 & 29,52 \\
Água & 46,23 & 2,16 & 61,19 & 2,86 & 54,01 & 2,52 & 56,5 & 2,64 \\
Áreas alteradas & - & - & - & - & 41,76 & 1,95 & 70,08 & 3,27 \\
Nuvem & 24,53 & 1,15 & 14,18 & 0,66 & - & - & - & - \\
Sombra & 9,73 & 0,45 & 9,34 & 0,44 & - & - & - & - \\
TOTAL & $2.141,26$ & 100 & $2.141,26$ & 100 & $2.141,26$ & 100 & $2.141,26$ & 100 \\
\hline
\end{tabular}

A figura 2 mostra a espacialização das classes de uso e cobertura da terra ao longo da bacia hidrográfica do rio Marapanim, nos quatro anos de análise. 


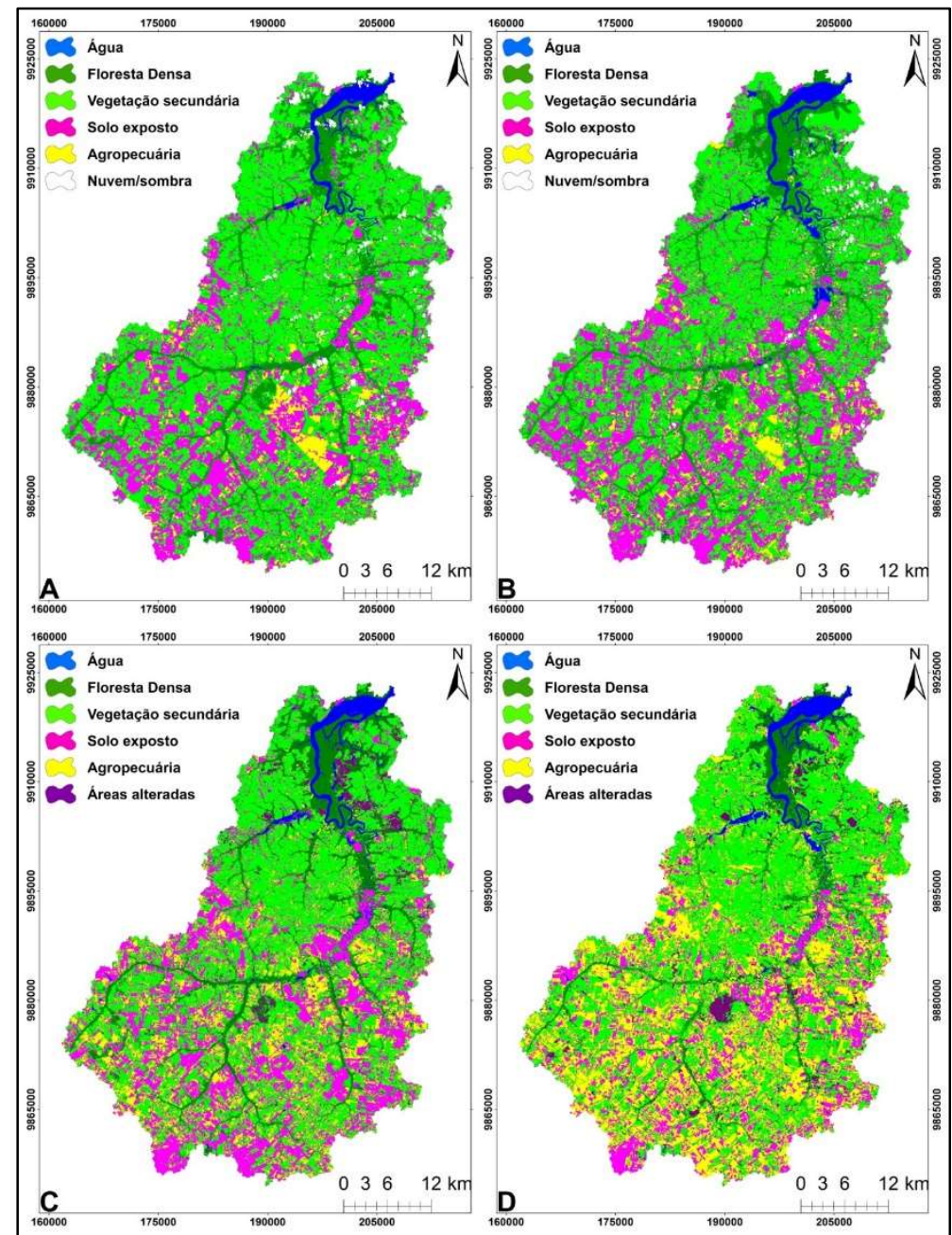

Figura 2: Uso e cobertura do solo na bacia hidrográfica do rio Marapanim, Pará, em A) 1988; B) 1998; C) 2008 e D) 2017.

\section{Detecção de mudança no período de 1988 a 2017}

As tabelas 3, 4 e 5 mostram as dinâmicas de uso e cobertura da terra na bacia hidrográfica nos períodos de 1988 a 2017, enfatizando as transformações e permanências das classes de uso do solo.

Tabela 3: Mudança de uso da terra no período de 1988 a 1998, com áreas em km².

\begin{tabular}{|c|c|c|c|c|c|c|c|c|c|}
\hline \multirow[b]{2}{*}{1998} & \multicolumn{9}{|l|}{1988} \\
\hline & $\mathrm{FD}$ & $\%$ & VS & $\%$ & SE & $\%$ & $\mathrm{~A}$ & $\%$ & Total \\
\hline FD & 210.01 & 73.79 & 74.4 & 6.6 & 0.12 & 0.03 & 0.24 & 0.2 & 284.77 \\
\hline VS & 56.1 & 19.71 & 779.81 & 69.13 & 158.9 & 33.83 & 49.93 & 41.34 & 1044.74 \\
\hline SE & 15.99 & 5.62 & 218.35 & 19.36 & 274 & 58.33 & 39.8 & 32.95 & 548.12 \\
\hline A & 2.52 & 0.89 & 55.51 & 4.92 & 36.72 & 7.82 & 30.82 & 25.52 & 125.57 \\
\hline Total & 284.62 & 100 & 1128.1 & 100 & 469.7 & 100 & 120.8 & 100 & \\
\hline
\end{tabular}

FD: Floresta densa; VS: Vegetação secundária; SE: Solo exposto; A: agropecuária

Tabela 4: Mudança de uso da terra no período de 1998 a 2008, com áreas em km².

\begin{tabular}{|c|c|c|c|c|c|c|c|c|c|}
\hline \multirow[b]{2}{*}{2008} & \multicolumn{9}{|l|}{1998} \\
\hline & FD & $\%$ & VS & $\%$ & SE & $\%$ & A & $\%$ & Total \\
\hline FD & 185.32 & 64.48 & 54.07 & 5.1 & 0.62 & 0.11 & 1.87 & 1.47 & 251.88 \\
\hline VS & 66.43 & 23.11 & 687.85 & 63.05 & 146.05 & 26.36 & 41 & 32.27 & 918.33 \\
\hline SE & 10.82 & 3.76 & 166.5 & 15.72 & 283.14 & 51.1 & 36.52 & 28.75 & 493.98 \\
\hline A & 8.31 & 2.89 & 149.83 & 14.14 & 119.48 & 21.56 & 47.6 & 37.47 & 324.22 \\
\hline $\mathrm{AA}$ & 16.52 & 5.75 & 21.05 & 1.99 & 1.71 & 0.31 & 0.05 & 0.04 & 39.33 \\
\hline Total & 287.4 & 100 & 1059.3 & 100 & 554 & 100 & 127 & 100 & \\
\hline
\end{tabular}

FD: Floresta densa; VS: Vegetação secundária; SE: Solo exposto; A: agropecuária; AA: Áreas Alteradas 
Tabela 5: Mudança de uso da terra no período de 2008 a 2017, com áreas em km².

\begin{tabular}{|c|c|c|c|c|c|c|c|c|c|c|c|}
\hline \multirow[b]{2}{*}{2017} & \multicolumn{11}{|l|}{2008} \\
\hline & FD & $\%$ & VS & $\%$ & SE & $\%$ & A & $\%$ & AA & $\%$ & Total \\
\hline FD & 143.1 & 53.59 & 14.47 & 1.54 & 0.45 & 0.09 & 1.37 & 0.42 & 2.27 & 5.46 & 162.7 \\
\hline VS & 85.55 & 32.03 & 639.92 & 68.07 & 63.11 & 12.56 & 93.66 & 28.71 & 22.11 & 53.2 & 904.35 \\
\hline SE & 3.12 & 1.17 & 61.06 & 6.5 & 187.51 & 37.32 & 58.92 & 18.06 & 1.19 & 2.86 & 310.8 \\
\hline A & 24.6 & 9.21 & 189.85 & 20.2 & 244.12 & 48.58 & 169.2 & 51.87 & 2.53 & 6.09 & 630.3 \\
\hline AA & 10.71 & 4.01 & 34.74 & 3.7 & 7.28 & 1.45 & 3.07 & 0.94 & 13.45 & 32.4 & 69.25 \\
\hline Total & 267.1 & 100 & 940.04 & 100 & 502.47 & 100 & 326.2 & 100 & 41.55 & 100 & \\
\hline
\end{tabular}

FD: Floresta densa; VS: Vegetação secundária; SE: Solo exposto; A: agropecuária; AA: Áreas Alteradas

\section{DISCUSSÃO}

A área ocupada por cada classe de uso do solo ao longo dos anos na bacia hidrográfica (Tabela 2) mostra que no primeiro ano de análise (1988), mais de 50\% da área da bacia já era de vegetação secundária. A expressiva participação da vegetação secundária na área da bacia já desde o primeiro ano pode ser justificada por essa região do nordeste paraense ser a mais antiga de colonização, além do marco histórico da construção da estrada de Ferro, que levaram a sucessivos eventos de desmatamentos e consequentemente à substituição da floresta nativa, o que caracterizou essa área como majoritariamente composta por vegetação secundária (VIEIRA et al., 2007).

No ano de 1998, houve uma pequena diminuição das áreas de vegetação secundária e um aumento de $13,4 \%$ das áreas de solo exposto e área urbana, estando isso associado ao significativo aumento populacional nesse período, fato esse que aumenta a área urbana e amplia as infraestruturas como ruas e estradas. Nesse ano houve ainda um aumento de 14,33\% das áreas de agropecuária em relação ao ano de 1988.

Uma década depois, em 2008, a vegetação secundária diminuiu em $12 \%$ em relação à 1998 , o que vai de encontro ao que relata Almeida et al. (2016), quando esses autores ressaltam que as áreas de vegetação secundária aumentaram no nordeste paraense nos últimos 30 anos. Nesse ano houve ainda a adição da classe áreas alteradas, a qual ocupou uma área de $41,76 \mathrm{~km}^{2}$, o que correspondeu a um percentual de $1,95 \%$.

No último ano de análise (2017), quando comparado ao ano anterior, as áreas de agropecuária aumentaram em $93,7 \%$ nesse período de nove anos, passando a ocupar $29,52 \%$ da área total da bacia em 2017 (Figura 2). Alves et al. (2018) enfatiza que as atividades agrícolas do nordeste do Pará são embasadas em hábitos familiares de produção e utilização de técnicas agrícolas rudimentares, resultando em desmatamento decorrentes do processo de derruba e queima da vegetação associado ao período de pousio, o que leva o pequeno agricultor a desmatar novas áreas para cultivo.

O estado do Pará se destaca como maior produtor nacional de mandioca em cultivo tradicional, sendo essa cultura a principal na região nordeste do estado, além da pimenta-do-reino e do maracujá, que possuem participação significativa na economia local dessa mesorregião (HOMMA et al., 2014). A área de floresta densa diminuiu em quase 40\% de 2008 para 2017, passando a ocupar nesse último ano, 7,66\% da área da bacia, enquanto que as áreas de vegetação secundária ocuparam $42,35 \%$ da área de estudo. Vieira et al. (2013) enfatizam que o nordeste paraense, especialmente a microrregião bragantina, foi uma das 
primeiras a ser submetida aos eventos de corte e queima para fins agrícolas, o que acarretou, ao longo de 135 anos de colonização com essa atividade, em uma paisagem ocupada por $10 \%$ dos remanescentes florestais da cobertura original e $43 \%$ de área de vegetação secundária.

A análise da matriz de mudança no primeiro período (1988 a 1998) mostra que de $284,77 \mathrm{~km}^{2}$ de floresta densa em 1988, 73,79\% permaneceram nessa classe em 1998, no entanto $19,71 \%$ foram transformados em vegetação secundária, associado às mudanças decorrentes das diferentes formas de uso e ocupação da terra que ocorrem nessa mesorregião. Cerca de 5,62\% da floresta densa foi transformada em solo exposto e 2,52 $\mathrm{km}^{2}$ se transformou em agropecuária (Tabela 3).

A maior parte da vegetação secundária em 1988 permaneceu em 1998 (69,13\%), porém 19,36\% foram convertidos em solo exposto e área urbana, 6,6\% evoluíram para floresta densa pelo processo de sucessão natural e 4,92\% passaram a ser agropecuária em 1998. Comportamento semelhante foi encontrado por Tamasaukas et al. (2016) ao analisar a paisagem da bacia do rio Caripi, também no nordeste do Pará, entre 1984 e 2013. Esses autores verificaram que ao longo de 10 anos (1984 a 1994), houve uma tendência de conversão de áreas de vegetação secundária em agricultura. Ao analisarem a paisagem ao longo de 10 anos em comunidades rurais do nordeste paraense, Watrin et al. (1998) constataram a tendência de conversão de áreas de vegetação secundária em solo exposto e pastagem.

Para as áreas de agropecuária, a transição deu-se prioritariamente para vegetação secundária (41,34\%). Essa dinâmica pode ser explicada pelo modelo de agricultura itinerante que predomina no nordeste paraense, realizado a partir de sucessivos eventos de derruba e queima, utilizando a vegetação secundária como elemento de pousio agrícola (WATRIN et al., 2009).

A matriz de mudança da década de 1998 a 2008 mostra que a classe de floresta densa diminuiu sua estabilidade, com transição principalmente para vegetação secundária $(23,11 \%)$, seguido da conversão para áreas alteradas (5,75\%) (Tabela 4). Como as áreas de floresta densa que ainda restam na bacia fazem parte das matas ciliares, essa dinâmica mostra o uso indevido das áreas de preservação permanente ao longo da bacia hidrográfica.

A classe de vegetação secundária diminuiu a sua estabilidade em relação ao período anterior, apresentando conversão prioritariamente para a classe de solo exposto $(15,72 \%)$, seguido da agropecuária $(14,14 \%)$, além de $21,05 \mathrm{~km}^{2}$ convertido para áreas alteradas, o que mostra o intenso uso do solo que vem ocorrendo ao longo da bacia hidrográfica do rio Marapanim.

A dinâmica de uso do solo no período de 2008 a 2017 mostra que a classe floresta densa diminuiu sua estabilidade em quase $17 \%$ em relação ao período anterior, com $53,59 \%$ de persistência para o ano de 2017 (Tabela 5). A principal conversão dessa classe deu-se para vegetação secundária (32\%) e agropecuária (9,21\%). De acordo com Cordeiro et al. (2017), a conversão de ambientes naturais em áreas agrícolas ocasiona mudanças na estrutura e funcionamento dos ecossistemas, impactando ao longo do tempo, os processos de regeneração e a disponibilidade de nutrientes.

Já a vegetação secundária possuiu uma permanência de $68 \%$, com maior conversão para a classe agropecuária (20,20\%). Comportamento semelhante foi encontrado por Sampaio et al. (2017) analisando a 
dinâmica de uso do solo no nordeste paraense no período de 2008 a 2012 (utilizando dados do projeto Terra Class), no qual houve uma transformação de $23 \%$ da classe vegetação secundária para a classe agricultura anual, com 51\% de permanência. Para esses autores, essa dinâmica está associada à expansão de cultivo do dendê no nordeste paraense, a qual, segundo Nahum et al. (2013), está relacionado a espaços marcados pela pecuária, de solo compactado, comprometimento da floresta primária e secundária, bem como da mata ciliar e dos corpos hídricos; outrossim, estes autores destacam ainda os problemas sociais ocasionados pela expansão da dendeicultura, tais como concentração de terra, descampesinização e ameaça à segurança alimentar.

Coelho et al. (2014) obtiveram resultados semelhantes ao estudarem a dinâmica da paisagem a partir das matrizes de transição obtidas pela classificação supervisionada de imagens Landsat 5 dos anos de 1991, 2000 e 2010 em uma bacia hidrográfica do semiárido brasileiro. Os autores constataram uma progressiva substituição das áreas de vegetação de caatinga aberta por áreas de pastagem/agricultura, assim como o crescimento acelerado dessa última classe na paisagem da bacia, chegando a ocupar $36 \%$ da bacia hidrográfica no último ano de análise.

A agropecuária permaneceu mais estável (51,87\%), com maior conversão para vegetação secundária (28,71\%), o que está associado a dinâmica da agricultura tradicional do nordeste paraense, à qual é praticada pela derruba e queima da vegetação nativa e introdução de um cultivo agrícola por um período de um a dois anos, seguido do pousio, período em que a vegetação secundária se restabelece na área (KATO et al., 1999). No entanto, Watrin et al. (2009) destacam que esse período de pousio vem diminuindo devido à necessidade de maior produção bem como a redução da disponibilidade de vegetações secundárias no nordeste paraense, o que aumenta a pressão sobre as áreas ripárias. Nesse último período, cerca de $18 \%$ das áreas de agropecuária foram convertidas em solo exposto. Fernandes et al. (2015) relatam que grande parte das áreas de solo exposto eram antes ocupadas por pastagens que posteriormente foram abandonadas.

\section{CONCLUSÕES}

As atividades de agropecuária aliado ao desmatamento foram responsáveis pela perda significativa de vegetação nativa da área de estudo, o que pôde ser comprovado pela diminuição da estabilidade da classe de vegetação densa ao longo do tempo. O estudo das modificações na paisagem da bacia hidrográfica permitiu constatar que as áreas dos remanescentes florestais de floresta densa estão sob pressão antrópica e assim se encontram mais frágeis. Essas áreas se localizam no entorno dos rios, constituindo as zonas ripárias que deveriam ser mantidas preservadas de acordo com o código florestal.

Deve-se considerar ainda a significativa pressão antrópica ocasionada pela expansão das áreas de agropecuária na bacia, a qual apresentou maior expansão no período de estudo, podendo-se esperar essa tendência de crescimento para os próximos anos, já que essa atividade predomina no nordeste paraense. Assim, esse estudo poderá subsidiar a formulação de políticas públicas específicas para a preservação dos remanescentes da vegetação natural da área da bacia, bem como para auxiliar na gestão ambiental futura. 


\section{REFERÊNCIAS}

ALVARES, C. A.; STAPE, J. L.; SENTELHAS, P. C.; GONÇALVES, J. L. M.; SPAROVEK, G.. Köppen's climate classification map for Brazil. Meteorologische Zeitschrift, Stuttgart, v.22, n.6, p.711-728, 2014. DOI: http://doi.org/10.1127/0941$\underline{2948 / 2013 / 0507}$

ALVES, R. J. M.; GONÇALVES, W. G.; GONÇALVES, J. P.; NUNES, G. L.; SILVA, E. R. M.; MAIA, J. S.; ADAMI, M.; NARVAES, I. S.. Análise do uso e ocupação do solo em Marapanim/PA a partir de dados do projeto Terraclass. Holos, Natal, v.3, p.81-90, 2018. DOI: http://doi.org/10.15628/holos.2018.2819

ALMEIDA, C. A.; COUTINHO, A. C.; ESQUERDO, J. C. D. M.; ADAMI, M. VENTURIERI, A.; DINIZ, C. G.; DESSAY, N.; DURIEUX, L.; GOMES, A. R.. High spatial resolution land use and land cover mapping of the Brazilian Legal Amazon in 2008 using Landsat-5/TM and MODIS data. Acta Amaz., Manaus, v. 46, n. 3, p. 291-302, 2016. DOI: http://dx.doi.org/10.1590/1809-4392201505504

BERTRAND, G.. Paisagem e geografia física global. Esboço metodológico. RA'EGA, Curitiba, v.8, n.8, p.141-152, 2004. DOI: http://dx.doi.org/10.5380/raega.v8i0.3391

BRAZ, L. C.; PEREIRA, J. L. G.; FERREIRA, L. V.; THALÊS, M. C.. $A$ situação das áreas de endemismo da Amazônia com relação ao desmatamento e às áreas protegidas. Bol. Geogr., Maringá, v.34, n.3, p.45-62, 2016. DOI: http://dx.doi.org/10.4025/bolgeogr.v34i3.30294

CARVALHO, R. G.. As bacias hidrográficas enquanto unidades de planejamento e zoneamento ambiental no Brasil. Caderno Prudentino de Geografia, Presidente Prudente, n.36, p.26-42, 2014.

CORDEIRO, I. M. C. C.; RANGEL-VASCONCELOS, L. G. T.; SCHWARTZ, G.. O manejo da floresta secundária na Amazônia oriental. In: CORDEIRO, I. M. C. C.; RANGELVASCONCELOS, L. G. T.; SCHWARTZ, G.; OLIVEIRA, F. A.. Nordeste Paraense: Panorama geral e uso sustentável das florestas secundárias. Belém: Edufra, 2017. p.163-190.

COELHO, V. H. R.; MONTENEGRO, S. M. G. L.; ALMEIDA, C. N.; LIMA, E. R. V.; NETO, A. R.; MOURA, G. S. S.. Dinâmica do uso e ocupação do solo em uma bacia hidrográfica do semiárido brasileiro. R. Bras. Eng. Agríc. Ambiental, Campina Grande, v.18, n.1, p.64-72, 2014. DOI: http://dx.doi.org/10.1590/S1415-43662014000100009

CHAVEZ, P. S.. An improved dark-object subtraction technique for atmospheric scattering correction of multispectral data. Remote Sensing of Environment, v.24, p.459-479, 1988.

CHAVEZ, P. S.. Radiometric calibration of Landsat thematic mapper multispectral images. Photogrammetric Engineering and Remote Sensing, v.55, p.1285-1294, 1989.

ESRI. What's new in ArcGIS 10?. Redlands: Esri, 2010.

EMBRAPA. Empresa Brasileira de Pesquisa Agropecuária. Sistema Brasileiro de Classificação de Solos. 3 ed. Brasília: Embrapa, 2013.
FERNANDES, M. R. M.; MATRICARDI, E. A. T.; ALMEIDA, A. Q.; FERNANDES, M. M.. Mudanças do Uso e de Cobertura da Terra na Região Semiárida de Sergipe. Floresta e Ambiente, Rio de Janeiro, v.22, n.4, p.472-482, 2015. DOI: http://dx.doi.org/10.1590/2179-8087.121514

FEARNSIDE, P. M.. Soybean cultivation as a threat to the environment in Brazil. Environmental Conservation, v.28, n.1, p. 23-28, 2001.

GARDNER, T. A. et al. A social and ecological assessment of tropical land uses at multiple scales: the Sustainable Amazon Network. Philosophical Transactions of the Royal Society B, v.368, n.1619, 2013. DOI: http://dx.doi.org/10.1098/rstb.2012.0166

HOMMA, A. K. O.; SANTOS, J. C.; SENA, A. L. S.; MENEZES, A. J. E. A.. Pequena produção na Amazônia: conflitos e oportunidades, quais os caminhos?. Amazônia: Ciência \& Desenvolvimento, Belém, v.9, n.18, p.137-154, 2014.

IBGE. Instituto Brasileiro de Geografia e Estatística. Manual Técnico da Vegetação Brasileira. 2 ed. Rio de Janeiro: IBGE, 2012.

LANDIS, J. R.; KOCH, G. G.. The measurement of observer agreement for categorical data. Biometrics, v.33, n.1, p.159174, 1977.

KATO, M. S. A.; KATO, O. R.; DENICH, M.; VLEK, P. L. G.. Firefree alternatives to slash-and-burn for shifting cultivation in the eastern Amazon region: the role of fertilizers. Elsevier Science, v.62, p.225-237, 1999. DOI: https://doi.org/10.1016/S0378-4290(99)00021-0

MAXIMIANO, L. A.. Considerações sobre o conceito de paisagem. RA'EGA, Curitiba, v.8, n.8, p.83-91, 2004. DOI: http://dx.doi.org/10.5380/raega.v8i0.3391

MOREIRA, T. R.; SANTOS, A. R.; DALFI, R. L.; CAMPOS, R. F.; SANTOS, G. A.; EUGENIO, F. C.. Confronto do uso e ocupação da terra em Apps no município de Muqui, ES. Floresta e Ambiente, Rio de Janeiro, v.22, n.2, p.141-152, 2015. DOI: http://dx.doi.org/10.1590/2179-8087.019012

NASCIMENTO, T. V.; FERNANDES, L. L.. Mapeamento de uso e ocupação do solo em uma pequena Bacia Hidrográfica da Amazônia. Ciência e Natura, Santa Maria, v.39, n.1, p.170178, 2017. DOI: http://dx.doi.org/10.5902/2179460X21737

NAHUM, J. S.; SANTOS, C. B.. Impactos socioambientais da dendeicultura em comunidades tradicionais na Amazônia paraense. Acta Geográfica, p.63-80, 2013. DOI: http://dx.doi.org/10.5654/acta.v0i0.1953

OLIVEIRA, D. G.; VARGAS, R. R.; SAAD, A. R.; ARRUDA, R. O. M.; DALMAS, F. B.; AZEVEDO, F. D.. Land use and its impacts on the water quality of the Cachoeirinha Invernada Watershed, Guarulhos (SP). Rev. Ambient. Água, Taubaté, v.13, n.1, p.1-17, 2018. DOI:

http://dx.doi.org/10.4136/ambi-agua.2131

PEREIRA, B. W. F.; MACIEL, M. N. M.; OLIVEIRA, F. A.; SILVA, H. A. S.; BRAGA, T. G. M.; FIGUEIREDO, D. B.. Estrutura da paisagem da bacia hidrográfica do rio Peixe-Boi com base na 
fragmentação da vegetação. Rev. Cienc. Agrar., Belém, v.58 n.2, p.159-167, 2015. DOI: http://dx.doi.org/10.4322/rca.1798

PRINA, B. Z.; TRENTIN, R.; ZIANI, P.. Ferramentas de geoprocessamento aplicadas no mapeamento do uso da terra no Município de Jaguari/RS. Ciência e Natura, Santa Maria, v.38, n.3, p.1217-1227, 2016. DOI: http://dx.doi.org/10.5902/2179460X18243

ROMERO-RUIZ, M. H.; FLANTUA, S. G. A.; TANSEY, K.; BERRIO, J. C.. Landscape transformation in savannas of northern South America: Land use/cover changes since 1987 in the Llanos Orientales of Colombia. Applied Geography, v.32, p.766-776, 2012.

SAMPAIO, S. M. N.; VENTURIERI, A.; CAMPOS, A. G. S.; ELLERES, F. A. P.. Dinâmica da cobertura vegetal e do uso da terra na mesorregião Nordeste Paraense. In: CORDEIRO, I. M. C. C.; RANGEL-VASCONCELOS, L. G. T.; SCHWARTZ, G.; OLIVEIRA, F. A.. Nordeste Paraense: Panorama geral e uso sustentável das florestas secundárias. Belém: Edufra, 2017. p.131-161.

SOUZA, S. R.; MACIEL, M. N. M.; OLIVEIRA, F. A.; JESUÍNO, S. A.. Dinâmica da paisagem na bacia hidrográfica do Rio Apeú, nordeste do Pará, Brasil. Rev. Acad. Ciênc. Agrár. Ambient., Curitiba, v.9, n.2, p.141-150, 2011.

TUCCI, C. E. M.. Hidrologia: ciência e aplicação. 2 ed. Porto Alegre: ABRH, 2001.

TAMASAUSKAS, P. F. L. F.; TAMASAUSKAS, C. E. P.. Mudanças de uso e cobertura da terra e escoamento superficial na bacia hidrográfica do rio Caripi/PA: uma análise a partir das geotecnologias. Revista GeoAmazônia, v.4, n.8, p.153-173, 2016.

VALE, J. R. B.; BORDALO, C. A. L.; FONSECA, L. C. M.. Análise do uso e cobertura da terra na Bacia Hidrográfica do rio Apeú, Nordeste Paraense, entre os anos de 1999 e 2014 Revista do Instituto Histórico e Geográfico do Pará, Belém, v.2, n.2, p.76-83, 2015. DOI: http://dx.doi.org/10.17553/2359-0831/ihgp.v2n2p76-83

VIEIRA, I. C. G.; TOLEDO, P. M.; ALMEIDA, A.. Análise das modificações da paisagem da região Bragantina, no Pará, integrando diferentes escalas de tempo. Ciência e Cultura, São Paulo, v.59, n.3, p.27-30, 2007.

VIEIRA, I. C. G.; ALMEIDA, A. S.. Dinâmica de uso da terra e regeneração de florestas em uma paisagem antrópica do leste do Pará. In: PERES, C.; BARLOW, J.; GARDNER, T.; VIEIRA, I. C. G.. Conservação da biodiversidade em paisagens antropizadas do Brasil. Curitiba: UFPR, 2013. p.83-93.

WATRIN, O. S.; GERHARD, P.; MACIEL, M. N. M.. Dinâmica do uso da terra e configuração da paisagem em antigas áreas de colonização de base econômica familiar, no nordeste do estado do Pará. Geografia, Rio Claro, v.34, n.3, p.445-472, 2009.

WANTRIN, O. S.; VENTURIERI, A.; SAMPAIO, S. M. N.. Análise Multitemporal do Uso da Terra e suas Interrelações com a Cobertura Vegetal em Comunidades Rurais do Nordeste Paraense. In: SIMPÓSIO BRASILEIRO DE SENSORIAMENTO REMOTO, 9. Anais. São José dos Campos: INPE, 1998.

A CBPC - Companhia Brasileira de Produção Científica (CNPJ: 11.221.422/0001-03) detém os direitos materiais desta publicação. Os direitos referem-se à publicação do trabalho em qualquer parte do mundo, incluindo os direitos às renovaç̃oses, expansões e disseminações da contribuição, bem como outros direitos subsidiários. Todos os trabalhos publicados eletronicamente poderão posteriormente ser publicados em coletâneas impressas sob coordenação da Sustenere Publishing, da Companhia Brasileira de Produção Científica e seus parceiros autorizados. Os (as) autores (as) preservam os direitos autorais, mas não têm permissão para a publicação da contribuição em outro meio, impresso ou digital, em português ou em tradução. 